\title{
Simulating the canopy reflectance of different Eucalypt genotypes with the DART 3D model
}

\author{
Julianne de Castro Oliveira*, Jean-Baptiste Féret, Flávio Jorge Ponzoni, Yann Nouvellon, \\ Jean-Philippe Gastellu-Etchegorry, Otavio Camargo Campoe, José Luiz Stape, Luiz Carlos \\ Estraviz Rodriguez, and Guerric le Maire
}

\begin{abstract}
Finding suitable models of canopy reflectance in forward simulation mode is a prerequisite for their use in inverse mode to characterize canopy variables of interest, such as Leaf Area Index (LAI) or chlorophyll content. In this study, the accuracy of the 3D reflectance model DART was assessed for canopies of different genotypes of Eucalyptus, having distinct biophysical and biochemical characteristics, to improve the knowledge on how these characteristics are influencing the reflectance signal as measured by passive orbital sensors. The first step was to test the model suitability to simulate reflectance images in the visible and near infrared. We parameterized DART model using extensive measurements from Eucalyptus plantations including 16 contrasted genotypes. Forest inventories were conducted and leaf, bark and forest floor optical properties were measured. Simulation accuracy was evaluated by comparing the mean top of canopy (TOC) bidirectional reflectance of DART with TOC reflectance extracted from a Pleiades very high resolution satellite image. Results showed a good performance of DART with mean reflectance absolute error lower than $2 \%$. Inter-genotype reflectance variability was correctly simulated, but the model didn't succeed at catching the slight spatial variation for a given genotype, excepted when large gaps appeared due to tree mortality. The second step consisted in a sensitivity analysis to explore which biochemical or biophysical characteristics influenced more the canopy reflectance between genotypes. These results present perspectives for using DART model in inversion mode.
\end{abstract}

Index Terms - DART, 3D modeling, eucalypt, radiative transfer model, remote sensing

\section{INTRODUCTION}

MONG the different methods to estimate A biophysical or biochemical characteristics of forest plantations, the analysis of the images measured by

Julianne de Castro Oliveira and Luiz Carlos Estraviz Rodriguez are with University of São Paulo, ESALQ/USP, Brazil (e-mail: juliannecoliveira@usp.br; lcer@usp.br), Jean-Baptiste Féret is with IRSTEA, UMR TETIS, BP5092 Montpellier, France (e-mail: jeanbaptiste.feret@teledetection.fr), Flávio Jorge Ponzoni is with INPE, Brazil (email: flavio@dsr.inpe.br), Yann Nouvellon is with CIRAD, UMR ECO\&SOLS, F-34398 Montpellier, France and with University of São Paulo, ESALQ/USP, Brazil (e-mail: yann.nouvellon@cirad.fr), Jean-Philippe Gastellu-Etchegorry is with CESBIO, France (e-mail : jean-philippe.gastelluetchegorry@cesbio.cnes.fr), Otavio Camargo Campoe is with Federal University of Santa Catarina, UFSC, Brazil (e-mail : otavio.campoe@ufsc.br), José Luiz Stape is with Suzano Pulp and Paper, Brazil (e-mail: stape@suzano.com.br) and Guerric le Maire is with CIRAD, UMR ECO\&SOLS, F-34398 Montpellier, France and with NIPE, UNICAMP, Campinas, Brazil (e-mail: guerric.le_maire@cirad.fr). sensors on orbital platforms is appropriate for large spatial scales studies. Images are converted into reflectance values for each spectral band of the image, and later used to retrieve biophysical parameters of the forest through empirical relationships, or through radiative transfer models (RTM) inversion [1] - [4].

RTM explicitly take into account stand structural characteristics (tree dimensions and positions, leaf area index, leaf angle distribution, crown cover, among others) and can simulate the quantitative value of the reflectance spectra of the canopy as observed on top of the canopy or by a sensor onboard a plane or a satellite. They are based on the knowledge of the physical laws that control the transfer and interaction of solar radiation in a vegetative canopy, in interaction with the soil [5]. The DART - Discrete Anisotropic Radiative Transfer - model [6], [7] is a comprehensive threedimensional model that simulates bidirectional reflectance and enables new possibilities of data analysis to evaluate, for example, canopy structure [8], radiative budget [9], [10], photosynthesis [10], chlorophyll content [11], [12], Leaf Area Index (LAI) [13], [14], among others.

Eucalypt plantations in Brazil cover 5.6 million ha, which accounts for $71.9 \%$ of planted forests in Brazil [15]. Currently, most areas are planted with several genotypes, mainly on clonal plantations, which have been tested and selected for distinct widespread soils and climatic Brazilian conditions [16]. These genotypes provide different phenotypes, with distinct canopy structure, leaf morphology and biochemical compounds and biomass production. Due to their high economic importance in Brazil, the understanding of how biophysical parameters of planted forests could explain the spatial-temporal growth dynamics and the estimation of such parameters through remotely-sensed images is of paramount importance [1], [17].

Eucalyptus plantations in Brazil present particular structures: they are planted at high densities (e.g. 1700 trees/ha), they generally have a low leaf area index compared to other dense forests, and they are planted in rows of different spacing (anisotropy). One supplementary difficulty comes from the variability of eucalypts species and genotypes that are planted in Brazil. The different genotypes can have different structural and biophysical properties, even at the same age, and these parameters may change the canopy reflectance in different magnitude. It is therefore necessary to understand better the drivers of the reflectance differences between genotypes to further assess if their estimation through inversion procedures is possible. 
Despite the successful use of physical approach of DART to retrieve canopies characteristics from inversion procedures, e.g. in [13], [18] - [20], few detailed studies have tested the efficiency of this 3D reflectance model in forward mode in forest canopy ecosystem [21], [22]. The first assumption of inversion procedure is the suitability of the RTM to simulate accurately the reflectance for a range of canopy characteristics corresponding at least to the range of application conditions. In this study, we parameterized DART model using an extensive in situ measurement dataset. Eucalyptus plantations of 16 different genotypes were used to test the accuracy of the simulations generated by DART when compared with experimental images acquired from a very high spatial resolution satellite, Pleiades. In a second step, we performed a sensitivity analysis using the parameters variability as they were measured in situ to quantify the effect of the main stand parameters (inter-genotype variability) on the canopy reflectance. We finally discussed the use of DART for inversion studies for these particular ecosystems.

\section{DATASET DESCRIPTION}

\section{A. Study site}

The study site is located in Itatinga Municipality, in the state of São Paulo, southeastern Brazil, 22 ${ }^{\circ} 58^{\prime} 04^{\prime \prime}$ 'S and $48^{\circ} 43^{\prime} 40^{\prime}$ 'W (Fig. 1), as part of the IPEF-Eucflux project. A genotype trial experiment of eucalypt was installed in November 2009 with 16 genotypes comprising several genetic origins from different eucalypt growing companies and regions in Brazil (G1, G2, G10: E. grandis; G3-G9, G11-G13, G15: E. grandis $x$ urophylla; G14: E. saligna; G16: E. camaldulensis $x$ grandis). Fourteen of these 16 genotypes were clones and two (G1 and G2) had seminal origin. Planting rows were mainly east-west oriented, with plant arrangement of $3 \mathrm{~m} \times 2 \mathrm{~m}$ (1666 trees per hectare). The experiment comprised 9 blocks, each having 16 treatments (genotypes) randomly distributed within a $4 \times 4$ subplot grid of 192 trees each (each subplot comprised 12 lines of 16 trees). Only the 10 lines and 10 rows central part of the subplot was analyzed (100 trees, $20 \mathrm{~m} \times 30 \mathrm{~m}$ area).

\section{B. In-situ measurements}

Forest inventories were carried out at 6, 12, 19, 26, 38, 52, 62 and 74 months of age. During these inventories, trunk diameter at breast height (DBH) and tree height were measured. Close to most of these dates, 10-12 trees were cut for each genotype to compute the biomass per compartment (leaves, branches, trunk and bark) to generate allometric relationships between trunk DBH and tree height, height to the base of the live crown, crown diameter and leaf area, as classically done in other studies in the same area[23] - [25]. All these allometric relationships presented good adjustments (e.g. $\mathrm{R}^{2} \sim 0.72,0.70$ and 0.88 , respectively, for crown diameter, crown height and leaf area) and included the age as an explanatory variable, allowing their application for each tree at each inventory date. LAI was calculated as the sum of the leaf area of each tree inside the plot divided by the plot area. Leaf angle distribution (LAD) was estimated from the leaf angles measured in the field for each genotype (as described in [17]) and adjusted with an ellipsoidal leaf angle density function. In each tree, a clinometer was used to measure the inclination of 72 leaves selected according to their position within the crown to be representative of the tree-scale distribution. The eucalypt stands were analyzed at the date of May, 2014 (54 months), corresponding to the date of satellite image acquisition, using interpolation of the field measurements between inventories at 52 and 62 months. For the leaf area, auxiliary leaf area index values retrieved from more frequent measurements on one of the genotypes allowed to improve the interpolation by considering a common seasonal variation.

Leaves, trunks and forest floor optical properties were measured on October 2015 with an ASD Field SpecPro (Analytical Spectral Devices, Boulder, Colorado, USA) spectrometer in the spectral range from 400 to $2500 \mathrm{~nm}$ with 1 $\mathrm{nm}$ intervals at 71 months after planting (in October 2015). In these dates, three trees per genotype were selected and for each tree, leaves were collected randomly at three crown layers (bottom, middle and top, divided by exact height proportions) and two horizontal positions in each layer (near and far from trunk), totaling two leaves per crown layer, six leaves per tree and 18 leaves per genotype. These leaves were kept cold and in the dark for less than one hour. Adaxial leaves reflectance and transmittance were measured in the laboratory using an integrating sphere (LI-COR 1800, LICOR, Inc., Lincoln, Nebraska, USA). Forest floor and bark reflectance were measured using a Contact Probe (ASD, Inc., Boulder, Colorado) on five different points for each genotype, in the same week without rain.

The spectral measurement date occurred more than one year after the satellite image acquisition. However, these component spectra have probably not evolved a lot during this interval: for leaves, there were no significant difference between months 52 and 72 for specific leaf area, water content, and SPAD values (measured with the SPAD-Minolta device) (data not shown). For trunk and forest floor, we assumed no changes, which seem a reasonable hypothesis for these components.

\section{Pleiades satellite images}

Very high spatial resolution multispectral scenes including four bands (blue: $430-550 \mathrm{~nm}$, green: $490-610 \mathrm{~nm}$, red: $600-$ $720 \mathrm{~nm}$ and near infrared: $750-950 \mathrm{~nm}$ ) from Pleiades satellite were used to validate DART simulations. The image (four bands) was acquired on May 2014, at 13:36 GMT, with the following angles: view azimuth $\varphi_{v}=180.03^{\circ}$, view zenith $\theta_{v}=13.40^{\circ}$, sun azimuth $\varphi_{s}=33.43^{\circ}$ and sun zenith $\theta_{s}=$ $44.48^{\circ}$. The image was orthorectified and projected. Polygons of each internal plot extension $(20 \mathrm{~m} \times 30 \mathrm{~m})$ were used to extract the radiance of the plots in each band of the Pleiades image. Transformation to TOA reflectance was performed, followed by an atmospheric correction to compute the reflectance of the top of canopy (TOC) of the scenes using the $6 \mathrm{~S}$ model and default atmospheric parameterization for this location [26]. 


\section{ANALYSES AND DART PARAMETERIZATION}

\section{A. DART parameterization}

DART was used in the ray tracing method and reflectance mode [6], [9] to simulate TOC bidirectional reflectance images. Simulations with DART were conducted on 4 wavebands corresponding to Pleiades sensor relative spectral response.

The input solar angles $\left(\theta_{s}\right.$ and $\left.\varphi_{s}\right)$ were computed knowing the local latitude, date and hour of satellite overpass. Image acquisition geometry $\left(\theta_{v}, \varphi_{v}\right)$ was obtained from metadata of Pleiades images. All DART simulated scenes were created using individualized positions and dimensions of the 192 trees of each subplot, but the output stand reflectance computation was restricted to an internal plot of $20 \mathrm{~m} \times 30 \mathrm{~m}$ (100 trees), to avoid any border effect. One scene was simulated for each of the 16 genotypes and 9 blocks at 54 months (corresponding to date May, 2014), with computing cubic cells of $0.50 \mathrm{~m}$ edge.

Input parameters related to the trees positions (coordinates $\mathrm{x}$ and $y$ in the plot), dimensions (e.g. crown diameter and height, DBH and total height), LAI and LAD for each tree were all insitu measurements (described on Section II.B.). For simulating tree crowns, we used a half ellipsoid shape, which typically fit well with the shape of eucalypts crown. Optical properties of the leaves were prescribed in function of the crown layer for each tree (upper, middle and lower) and in function of the genotype, such as the bark and forest floor reflectance. In these canopies, the branches are very thin and represent a very small absorbing surface in comparison to leaves and barks, and therefore they were not simulated.

\section{B. Comparison between simulated and satellite images}

The accuracy of the simulated reflectance TOC scenes from DART was checked against the TOC reflectance obtained from Pleiades scenes, for all 4 broadbands (blue, green, red, and NIR), 9 blocks and 16 genotypes. The overall accuracy level for simulating eucalypt plantations was expressed by the mean absolute error (MAE) of each spectral band [27]:

$$
M A E_{\lambda}=\frac{1}{n} \sum_{i=1}^{n}\left|R_{\text {Pléiades }, \lambda}(i)-R_{D A R T, \lambda}(i)\right|,
$$

where $R_{\text {Pléiades }, \lambda}$ is the reflectance measured by Pleiades satellite for spectral band $\lambda, R_{D A R T, \lambda}$ is the reflectance simulated by DART for the same spectral band, and $n$ is the number of samples ( $n=144$ plots, product of 9 blocks by 16 genotypes). The systematic error (BIAS), root mean square error (RMSE) and the determination coefficient $\left(\mathrm{R}^{2}\right)$ were also computed, both at genotype scale (averaged by blocks, so $\mathrm{n}=16$ for each band), or for each genotypes for inter-block variability (so $n=9$ for each band and each genotype).

\section{Sensitivity analysis of DART for eucalypt plantations}

A simple sensitivity analysis was performed to better understand the effect of inter-genotype differences in structure, biophysical and biochemical parameters on the simulations output. We selected one of the genotype (the G3, that represents the main genotype planted around the experimental area), grown in one of the block (B2, where the plots shows good growth and health) as an example. For each of the parameter listed below, we exchanged one by one the G3 value by the value of another genotype of the same block B2. The range and variation of these values reflected therefore the real inter-genotype variability as it appears on in situ measurements, which enabled more realistic description and analysis of parameters influences on the reflectance. For instance, the LAI of G3 was replaced by the one of G1, the DART reflectance in the four bands were simulated, then a new simulation was performed with the LAI of G2, etc. At the end, we computed the average, variance and produced a boxplot figure for each parameter at each reflectance band. The tested parameters were LAI, LAD, leaf, bark and forest floor optical properties (reflectance), trees dimensions (tree and crown height, crown diameter and $\mathrm{DBH}$ ), and row azimuth. Note that for the particular case of row azimuth, we changed the orientation by using the orientation of the other blocks one by one, and this is not linked to the genotype. However, including this variability will give more precise information on the importance of this factor. This procedure allows us to better understand which parameters drive the inter-genotypes variability in reflectance.

\section{RESULTS}

\section{A. Differences between genotypes structural and biochemical properties}

The main characteristics of the genotypes (DBH, height, leaf area, LAI, crown length, crown diameter, leaf angle and mortality) based on field measurements and used for DART parameterization are shown in Fig. 2, together with their interblock repetitions. Overall, we can see that the tree dimensions and structural properties are similar between genotypes having the same age, and high local variability. However, when looking closer, there are some differences between genotypes. The DBH and height values were very similar between genotypes, with higher variability for the seminal material G1 and G2, and higher growth homogeneity of the clonal materials. G16 was the most homogeneous clone. G7, G12 and G16 presented the lowest leaf area values and lowest variability between trees. LAI for all genotypes was around 3$6 \mathrm{~m}^{2} / \mathrm{m}^{2}$ and with small spatial variability, mainly for G12 and G16. G10, G11 and G13 presented the highest and G16 the lowest LAI values. In contrast with the tree height, the crown length varied more between genotypes. Similar with tree DBH and height, the crown diameter exhibited little variability across genotypes, with a median around $3 \mathrm{~m}$ indicating that at this age (54 months) the trees inside the plots are exploring more or less the space they individually have $(3 \mathrm{~m} \times 2 \mathrm{~m})$. Note that there was a small measured difference between within rows and between-rows crown diameters that was included in the simulations. The leaf inclination angle showed high between-trees variability, mostly driven by differences in tree size since there were strong canopy vertical gradients of leaf inclination angles [17]. G16 had the highest leaf inclination angles with low variability between trees. Mortality exhibited large variability across genotypes, with the highest values (reaching around $20 \%$ ) for genotypes G1, G3, G6 and G13. For other genotypes, the mortality was lower 
than $10 \%$, which are common values for eucalypt plantations [28].

Leaves, trunks and forest floor optical properties are shown on Fig. 3 for each genotype. Leaf reflectance (shown on Fig. 3 for expanded mature leaves of the middle crown layer) exhibited high absorption peaks in the blue and red regions and high NIR reflectance for all genotypes. Note that the reflectance ranking between genotypes was conserved for all wavelengths in the visible but changed further in the NIR and MID regions. There were larges differences of bark reflectance between genotypes. Interestingly the reflectance was very high in the visible and NIR regions compared to leaf reflectance. Some spectra clearly show an absorption feature in the red region. Forest floor reflectance showed similar pattern for all genotypes, but with a high inter-genotype variability, with low reflectance in the visible region and increasing values along the spectrum, and a mild absorption peak in the water absorption band $(1400 \mathrm{~nm})$.

Fig. 4 shows the leaves reflectance in the green, red and near infrared bands for each crown level (bottom, middle and top) and genotypes. There was no significant difference between crowns layers, significant differences between genotypes and no significant differences for the interaction genotype $\times$ crown layers for each band (N-Way ANOVA under Matlab 2013a, $\alpha=0.05$ ). Note that statistical analysis was done using all measured reflectance data instead of the average values shown on Fig. 4.

\section{B. Comparison of DART simulations with Pleiades satellite image}

The TOC reflectances simulated by DART and acquired by the Pleiades sensor at the four multispectral bands for each genotype are shown on Fig. 5, averaged by genotype and with standard deviation. In general, the mean TOC reflectances from DART simulations were in good agreement with the mean TOC reflectance of the Pleiades scenes for all four bands and genotypes. Discrepancies were found mainly for the blue band $(430-550 \mathrm{~nm})$ for all genotypes, and some discrepancies appeared in the near infrared band $(750-950 \mathrm{~nm})$ for some genotypes (e.g., genotypes 5, 8 and 12). A numerical comparison between the reflectance simulated by DART and acquired by Pleiades scenes was performed using the MAE, RMSE and $\mathrm{R}^{2}$ for all blocks and genotypes in each band (Table 1). The minimum and maximum range of $\mathrm{R}^{2}$ values computed for each genotype for the four bands are also presented.

The MAE values were low for all bands $(<0.0195)$, with the lowest values for the green band. Higher values were found for blue and NIR bands, which corroborates the results of Fig. 5. BIAS, that represents the average difference between Pleiades and DART reflectance, was negative and indicated that TOC reflectances simulated by DART model were, in general, slightly higher than TOC reflectances derived from Pleiades images. RMSE were also low $(<0.023)$, mainly for the bands in the visible domain $(<0.0023)$. NIR band had the higher value. The $\mathrm{R}^{2}$ best performance was for red and NIR bands and worst for blue band. The $\mathrm{R}^{2}$ for each genotype computed with the different blocks (spatial variability) in all bands showed a wide range of values. The spatial variability of some genotypes was correctly simulated whereas others were not significant.

\section{TABLE 1}

MEAN ABSOLUTE ERROR (MAE), SYSTEMATIC ERROR (BIAS), ROOT MEAN SQUARE ERROR (RMSE) AND DETERMINATION COEFFICIENT $\left(\mathrm{R}^{2}\right)$ FOR SIMULATED BANDS (BLUE, GREEN, RED AND NIR) IN RELATION TO PLEIADES BANDS, AVERAGED BY GENOTYPE AND BLOCK. $\mathrm{R}^{2}$ OF GENOTYPES (MIN. MEAN - MAX.) IS THE MINIMUM, MEAN AND MAXIMUM $\mathrm{R}^{2}$ VALUES IN EACH BAND FOR THE GENOTYPES, COMPUTED ON THE INTER-BLOCK VARIABILITY.

\begin{tabular}{cccccc}
\hline Band & MAE & BIAS & RMSE & $\mathrm{R}^{2}$ & $\begin{array}{c}\mathrm{R}^{2} \text { of genotypes } \\
\text { (min. - mean- max.) }\end{array}$ \\
\hline Blue & 0.0180 & -0.0180 & 0.00106 & 0.41 & $0.0003-0.11-0.79$ \\
Green & 0.0063 & -0.0063 & 0.00223 & 0.43 & $0.0003-0.12-0.88$ \\
Red & 0.0170 & -0.0170 & 0.00104 & 0.51 & $0.0003-0.12-0.75$ \\
NIR & 0.0194 & -0.0044 & 0.02200 & 0.55 & $0.0023-0.28-0.91$ \\
\hline
\end{tabular}

An example of the level of detail of trees parameterization on DART simulated scenes compared with Pleiades scenes is shown on Fig. 6 for the near infrared band of G14, block 4 . (scenes with $0.50 \mathrm{~m}$ and $2 \mathrm{~m}$ of spatial resolution). The near infrared $(2.0 \mathrm{~m}$ of spatial resolution) and panchromatic band of Pleiades $(0.50 \mathrm{~m}$ of spatial resolution) scenes for the same G14 and block 4 are also presented. The Pleiades panchromatic was chosen to present this example, due to the higher spatial resolution of this band. This visual comparison illustrates how the DART model represents the canopy. We can see that DART simulations are in accordance with the image in terms of shadow proportion, gaps, row orientations, textures and object dimensions. However, the model cannot reach the level of detail for a use on a tree-by-tree analysis in this type of canopy structure.

\section{Sensitivity Analysis}

The results of the sensitivity analysis of the simulated reflectance for the blue, green, red and NIR bands according to stand parameters (LAI, LAD, leaf, bark and forest floor optical properties - reflectance, trees dimensions and row azimuth) are presented in Fig. 7. The behavior of real range variation of each parameter individually (without interaction between them) on the average canopy reflectance was presented together to compare their magnitude. LAI, leaf reflectance, trees dimensions and row azimuth had the highest sensitivity and explain most of the difference between genotypes in the visible bands. These variability were of the same order of magnitude as the variability due to row orientation. Bark and forest floor reflectance and LAD showed the weakest sensitivity in these bands despite their intergenotype variability being relatively high. The NIR band showed similar reflectance results among the replacing tests, but with higher inter-genotype standard deviations compared to the others bands. The LAD, bark and forest floor reflectance showed higher influence in the NIR band compared to visible bands.

\section{DISCUSSION}

\section{A. Parameterization of DART}

Overall, the differences between eucalypt trees of different genotypes and locations were not very large for many of the 
parameters. However, the final importance of a parameter to explain the difference in TOC reflectance between genotypes (and/or locations) is a conjunction of the inter-genotype variability (or spatial variability) of this parameter, and the sensitivity of that parameter in the model. It is therefore important, before setting some of the DART parameters to constants (and therefore not explaining the genotype or spatial variability), to model the system with the maximum precision, and simplify afterwards if possible. The model parameterization is therefore a critical step of this work.

The leaf reflectance was shown to be different between genotypes, reflecting differences in pigment contents, and internal structure of leaves. A more detailed analysis could be done to assess which leaf structural or biochemical characteristics could explain this reflectance variability, but such analysis is out of the scope of the study: here we focused our analysis on the macro-scale differences between genotypes, and leaf reflectance was therefore an input parameter of DART.

The high inter-genotypes difference of bark reflectance (Fig. 3) was expected, since their color and roughness was extremely different in the field. The absorption feature in the red is associated to the presence of chlorophyll pigments in the bark surface for some of the genotypes, as observed in many other studies (e.g. in [29], [30]). There was also a high intergenotype variability on forest floor reflectance (Fig. 3), mainly in the NIR and MID regions. This behavior is due to the different composition of the forest floor materials (e.g. green or yellowing leaves just fallen and dead dry leaves, bark and branches proportion, leaf sizes), their structural variance, moisture content and decomposition stage [31]; which directly influences the reflectance.

The ANOVA analysis of the leaf reflectance for bottom, middle and top crown layers in the green, red and NIR bands (Fig. 4) showed that there was no statistical significant difference between bottom, middle and top crown layers but there were differences between genotypes considering all crown layers. Therefore, the use of different spectra for upper, middle and lower part of the canopy could be unnecessary for simulating reflectance in these wavebands. However, since some genotypes showed different spectra for upper layer, which could be locally important for TOC simulation, we preferred to keep this detailed description in the simulations. Also, the leaves inside each crown layers have different combinations of development stages (juveniles and mature). Generally there is a gradient of these development stages inside crown, with more juvenile leaves in the top layer and more mature leaves in the bottom. Mature leaves have more pigments, higher mass per area than juvenile [32], and different internal structure, which directly influence the reflectance in the visible and NIR wavelengths. However, our results did not clearly show any vertical trend of reflectance between crown layers. The explanation is that the proportion of juvenile leaves in the top layer is variable between genotypes, and between trees of different heights.

\section{B. Suitability of DART for TOC simulations}

Assessing if a RTM is suitable to simulate a given ecosystem depends on the objective of the study. In this study, we can distinguish the results in function of the level of variability of the observed canopy, i.e., evaluating the degree of precision of DART for simulating i) a "typical" Eucalyptus plantation reflectance, ii) inter-genotype reflectance variability and iii) the inter-block reflectance variability for the same genotype.

Our results showed that the DART model was suitable to simulate Eucalyptus plantation in general, with their very high tree density, their tall trunks, bright forest floor, and ellipsoidal form of their crown (Fig. 5): this is especially underlined by the low MAE obtained for this ecosystem (lower than 2\%). The inter-genotype variability of reflectance comes from the variability of many structural and biochemical parameters of the ecosystem, as represented in Fig. 2 and Fig. 3 (e.g. optical properties of the different components, leaf angles, dimensions of trees, etc.). This inter-genotype variability was adequately simulated as could be seen on Fig. 5 and Table 1, with coefficients of determination $>0.41$ for all spectral bands, and of 0.55 in the NIR bands. Such a bias for blue band could come from residual atmospheric effects not properly taken into account in the atmospheric correction of the Pleiades images, which was based on standard atmospheric parameterization of $6 \mathrm{~S}$ in absence of local measurements of atmospheric water, ozone and aerosols contents.

Finally, the simulations of the spatial variability between blocks, for each genotype were not adequately simulated for most genotypes. There were very low average coefficients of determination in all bands considering each genotype for all blocks. The spatial variability for a given genotype is more difficult to assess by simulation, mainly because of the low variability existing between these blocks. Therefore, the precision of the simulation is not sufficient to catch up this spatial variability. However, some genotypes had higher mortality rates (e.g. G1, G3, G6 and G13), which created large gaps in the canopy and increased the variability to a range possible to simulate (high $\mathrm{R}^{2}$ scores). As a consequence, the use of DART model in inversions mode for these ecosystems would gain precision if the genotype is already known, and in areas where the proportion of gaps remains low. Moreover, the row orientation could also act as a confounding factor and should also be prescribed prior to inversion, i.e. a pre-analysis of row orientations needs to be carried on.

In terms of bi-directional TOC reflectance, the comparison between simulated and real satellite scenes from forest stands is a difficult task, since the reflectance image is dominated by the macroscopic properties of the illuminated and shadowed crowns as well as ground surface [33], as illustrated in Fig. 6, at very high resolution.

Our results confirm the ability of DART to simulate remote sensing data under several eucalypt forest conditions. Some comparisons between DART simulations and forest ecosystems reflectance was also done in [21], [22] and the main conclusions were that DART showed very low pixels spectral dissimilarity compared with IKONOS images and $\mathrm{R}^{2}$ of 0.48 for a pixel-wise comparison with APEX imaging spectrometer, respectively. DART has been successfully compared with other 3D models throughout the RAdiative transfer Models Intercomparison - RAMI exercise [34], [35] under several conditions. Our results extend DART model validation on real measured dataset of individualized trees and 
stands of Eucalyptus plantations, which have particular characteristics (e.g. a high tree density but rather low LAI, lots of trunk surface but few branches).

\section{Source of the inter-genotype reflectance variability}

After having tested the model suitability to simulate intergenotype TOC reflectance variability, we seek to address which of the stand structural or biochemical parameters (LAI, $\mathrm{LAD}$, leaf, bark and forest floor optical properties, trees dimensions and row orientation) influences more the reflectance between genotype (Fig. 7). These parameters were chosen since they are the main input parameters of DART.

The LAI was one of the most influencing parameter for explaining the difference of reflectance between genotypes. Numerous studies have proved that vegetation reflectance is strongly affected by LAI in the entire spectra, but more in the NIR [36] - [38]. The leaf reflectance, which reflects in the visible the different leaves pigments contents, was another very important factor driving the canopy reflectance, mainly in the visible region. These results agree with [37], which performed a sensitivity analysis of vegetation reflectance and found more influence of leaves pigments content in the visible and LAI in the NIR regions at canopy scale. They also showed a weak effect of leaf angle at this scale.

The crown dimensions also explained the difference of TOC reflectance between genotypes (Fig. 7), as shown in other studies [39]. This variable, jointly with the row azimuth, mainly drives the proportion of visible soil between rows and the proportion of shaded/illuminated crowns on the image. The presence of empty spaces (dead trees) in some of the plots increased even more this heterogeneity, which also increased the contribution of this parameter to the inter-genotype and spatial variability of TOC reflectance.

Some of the parameters tested here showed moderate sensitivity on simulated TOC reflectance, which is the case for bark and forest floor reflectance. Therefore, average values could have been chosen for these parameters, and could simplify further inversions. In contrast, TOC reflectance showed high sensitivity to LAI, leaf reflectance, trees dimensions and row azimuth. It seems therefore important to perform genotype-specific inversion in the future, or grouping genotypes for their crown dimensions. Also, knowledge of the row orientation will be critical for inversion purposes. Further step will be to simulate a comprehensive database along eucalypts growth stages for different genotypes, and use this database to estimate some variables such as the LAI or chlorophyll content through inversion procedures. Our first sensitivity analysis can further help distinguish the inversion errors coming from the model itself or coming from the inversion methodology (algorithm, constraints, etc.).

These sensitivity analysis results confirm the relevance of using 3D models such as DART, as they are particularly suitable to explicit the influence of tree shape, leaf pigments and plot heterogeneity on the canopy reflectance of different genotypes and row orientations.

\section{CONCLUSION}

In this study we tested DART model to simulate Eucalyptus plantation reflectance, their difference between genotypes and between plots for a given genotype. DART was reliable for eucalypts plantation simulation in general, and adequately simulated the difference of reflectance between 16 genotypes including the mostly planted ones in the region, and some particular genotypes (e.g. G16: E camaldulensis $x$ grandis). However, the local difference of reflectance was correctly simulated only when the range of TOC reflectance was high for a given genotype, which occurred mainly through local mortality.

The difference of TOC reflectance in the visible bands between genotypes is mainly explained by differences in LAI, leaf optical properties and row orientation. In the NIR, the same parameters influence the TOC canopy, together with the tree dimensions. Leaf angles, bark and forest floor reflectance have a smaller effect in comparison to the other parameters, although their inter-genotype variability was large.

Successful test of DART in forward mode for simulating the TOC reflectance of these different genotypes open possibilities for parameter estimation through model inversion procedures for eucalypt plantations.

\section{ACKNOWLEDGMENT}

This study was funded by Forestry Science and Research Institute - IPEF (EUCFLUX project - funded by Arcelor Mittal, Cenibra, Copener, Duratex, Fibria, International Paper, Klabin, Suzano and Vallourec), the HyperTropik project (TOSCA program grant of the French Space Agency, CNES), CNPq, CAPES and the Centre de Coopération Internationale en Recherche Agronomique pour le Développement - CIRAD. Pleiades image was acquired in the frame of GEOSUD program, a project (ANR-10-EQPX-20) of the program "Investissementsd'avenir" managed by the French National Research Agency. We are grateful to Eloi Grau (IRSTEA) for support in running the program, José Guilherme Fronza for field work, and the staff at the Itatinga Experimental Station, in particular Rildo Moreira e Moreira (ESALQ, USP) and Eder Araujo da Silva (http://www.floragroapoio.com.br) for their technical support.

\section{REFERENCES}

[1] G. le Maire, C. Marsden, Y. Nouvellon, J. L. Stape, F. J. Ponzoni, "Calibration of a species-specific spectral vegetation index for leaf area index (LAI) monitoring: example with MODIS reflectance time-series on Eucalyptus plantations," Remote Sens., v. 4, no. 12, pp. 3766-3780, Nov., 2012.

[2] C. Atzberger, R. Darvishzadeh, M. Immitzer, M. Schlerf, A. Skidmore, G. le Maire, "Comparative analysis of different retrieval methods for mapping grassland leaf area index using airborne imaging spectroscopy," Int. J. Appl. Earth Observ. Geo, v. 43, pp. 19-31, Dec., 2015.

[3] C. Atzberger, R. Darvishzadeh, M. Schlerf, G. le Maire,"Suitability and adaptation of PROSAIL radiative transfer model for hyperspectral grassland studies," Remote Sens.Letters, v. 4, no. 1, pp. 55-64, Jan., 2013.

[4] G. le Maire, C. François, K. Soudani, D. Berveiller, J-Y. Pontailler, N. Bréda, H. Genet, H. Davi, E. Dufrêne, "Calibration and validation of hyperspectral indices for the estimation of broadleavedforest leaf chlorophyll content, leaf mass per area, leaf area index and leafcanopy 
biomass," Remote Sens. Environ., v. 112, no. 10, pp. 3846-3864, Oct., 2008.

[5] J-P. Gastellu-Etchegorry, V. Bruniquel-Pinel, "A modeling approach to assess the robustness of spectrometric predictive equations for canopy chemistry," Remote Sens. Environ., v. 76, no. 1, pp. 1-15, Apr., 2001.

[6] J-P. Gastellu-Etchegorry, F. Zagolski, J. Romier, "A simple anisotropic reflectance model for homogeneous multilayer canopies," Remote Sens. Environ., v. 57, no. 1, pp.22-38, July, 1996.

[7] J-P. Gastellu-Etchegorry,T. Yin, N. Lauret, T. Cajgfinger, T. Gregoire, E. Grau, J-B. Feret, M. Lopes, J. Guilleux, G. Dedieu, Z. Malenovský, B. D. Cook, D. Morton, J. Rubio, S. Durrieu, G. Cazanave, E. Martin, T. Ristorcelli, "Discrete Anisotropic Radiative Transfer (DART 5) for modeling airborne and satellite spectroradiometer and LIDAR acquisitions of natural and urban landscapes,"Remote Sens., v. 7, no. 2, pp. 1667-1701, Feb., 2015.

[8] N. Barbier, P. Couteron, J-P. Gastellu-Etchegorry, C. Proisy, "Linking canopy images to forest structural parameters: potential of a modeling framework," Ann. For. Sci, v. 69, no. 2, pp. 305-311, Mar., 2012.

[9] J-P. Gastellu-Etchegorry, E. Martin, F. Gascon, "DART: a 3D model for simulating satellite images and studying surface radiation budget," Int. J. Remote Sens., v. 25, no. 1, pp. 73-96, Jan., 2004.

[10] V. Demarez, J-P. Gastellu-Etchegorry, P. Mordelet, C. Tosca, G. Marty, P. Guillevic, "Modeling of the radiation regime and photosynthesis of a finite canopy using the DART model. Influence of canopy architecture of canopy architecture assumptions and border effects," Agronomie, v. 20,no.3,pp.259-270, Jan., 2000.

[11] Z. Malenovský, L. Homolová, R. Zurita-Milla, P. Lukeš, V. Kaplan, J. Hanuš, J-P. Gastellu-Etchegorry, M. E. Schaepman, "Retrieval of spruce leaf chlorophyll content from airborne image data using continuum removal and radiative transfer," Remote Sens. Environ., v. 131, pp. 85102, Jan., 2013.

[12] V. Demarez, J-P. Gastellu-Etchegorry, "A modeling approach for studying forest chlorophyll content," Remote Sens. Environ., v. 71, no. 2, pp. 226-238, Feb., 2000.

[13] A. Banskota, S. P. Serbin, R. H. Wynne, V. A. Thomas, M. J. Falkowski, N. Kayastha, J-P. Gastellu-Etchegorry, P. A. Townsend, "An LUT-Based inversion of DART model to estimate forest LAI from hyperspectral data," IEEE J. Sel. Topics Appl. Earth Observ. Remote Sens., vol. 8, no. 6, pp. 3147-3160, June, 2015.

[14] A. Banskota, R. H. Wynne, V. A. Thomas, S. P. Serbin, N. Kayastha, JP. Gastellu-Etchegorry, P. A. Townsend "Investigating the utility of wavelet transforms for inverting a 3-D radiative transfer model using hyperspectral data to retrieve forest LAI," Remote Sens., v. 5, pp. 26392659, May, 2013.

[15] Indústria Brasileira de Árvores, "Relatório IBÁ," IBÁ, Brasília, GO, 2015.

[16] J. L. M. Gonçalves, C. A. Alvares, A. R. Higa, L. D. Silva, A. C. Alfenas, J. Stahl, S. F. B. Ferraz, W. P. Lima, P. H. S. Brancalion, A. Hubner, J-P. Bouillet, J-P. Laclau, Y.Nouvellon, D. Epron, "Integrating genetic and silvicultural strategies to minimize abiotic and biotic constraints in Brazilian eucalypt plantations," Forest Ecol. Manag., v. 301, pp.6-27, Aug., 2013.

[17] G. le Maire, C. Marsden, W. Verhoef, F. J. Ponzoni, D. Lo Seen, A. Bégué, J. L. Stape, Y. Nouvellon, "Leaf area index estimation with MODIS reflectance time series and model inversion during full rotations of Eucalyptus plantations," Remote Sens. Environ., v. 115, no. 2, pp. 586-599, Feb., 2011.

[18] L. Yáñez-Rausell, Z. Malenovský, M. Rautiainen, J. G. Clevers, P. Lukeš, J. Hanuš, M. E. Schaepman, "Estimation of spruce needle-leaf chlorophyll content cased on DART and PARAS canopy reflectance models," IEEE J. Sel. Topics Appl. Earth Observ. Remote Sens., vol. 8, no. 4, pp. 1534-1544, Apr., 2015.

[19] D. Kimes, J-P. Gastellu-Etchegorry, P. Estève, "Recovery of forest canopy characteristics through inversionof a complex 3D model," Remote Sens. Environ., v. 79, no. 2, pp. 320-328, Feb., 2002.

[20] J-P. Gastellu-Etchegorry, F. Gascom, P. Estève, "An interpolation procedure for generalizing a look-up table inversion method," Remote Sens. Environ., v. 87, pp. 55-71, Sep., 2003.

[21] S. Couturier, J-P. Gastellu-Etchegorry, P. Patiño, E. Martin, "A modelbased performance test for forest classifiers on remote-sensing imagery,"Forest Ecol. Manag., v. 257, no. 1, pp. 23-37, Jan., 2009.

[22] F. D. Schneider, R. Leiterer, F. Morsdorf, J-P. Gastellu-Etchegorry, N. Lauret, N. Pfeifer, M. E. Schaepman, "Simulating imaging spectrometer data: 3D forest modeling based on LiDAR and in situ data," Remote Sens. Environ., v. 152, pp. 235-250, Sep., 2014.
[23] J-P. Laclau, J-P. Bouillet, J. L. M. Goncalves, E. V. Silva, C. Jourdan, M. C. S. Cunha, R. M. Moreira, L. Saint-Andre, V. Maquere, Y. Nouvellon, J. Ranger, "Mixed-species plantations of Acacia mangium and Eucalyptus grandis in Brazil -1. Growth dynamics and aboveground net primary production," Forest. Ecol. Manag., v. 255, pp. 3905-3917, June, 2008.

[24] G. le Maire, Y. Nouvellon, M. Christina, F.J. Ponzoni, J.L. M.Gonçalves, J-P. Bouillet, J-P. Laclau, "Tree and stand light use efficiencies over a full rotation of single- and mixed-species Eucalyptus grandis and Acacia mangium plantations,"Forest. Ecol. Manag., v. 288, pp. 31-42, Jan., 2012.

[25] M. Christina, Y. Nouvellon, J-P. Laclau, J. L. Stape, J-P. Bouillet, G. R. Lambais, G. le Maire, "Importance of deep water uptake in tropical eucalypt forest," Funct. Ecol., v. 31, pp. 509-519, Feb., 2017.

[26] E. F. Vermote, D. Tanre, J. L. Deuze, M. Herman, J-J. Morcette, "Second simulation of the satellite signal in the solar spectrum, 6S: An overview,"IEEE Trans. Geosci. Remote Sens., v. 35, no. 3, pp. 675-686, May, 1997.

[27] C. J. Willmott, K. Matsuura, "Advantages of the mean absolute error (MAE) over the root mean square error (RMSE) in assessing average model performance,"Climate Res., v. 30, no. 1, pp. 79-82, Dec., 2005.

[28] J. Zhou, C. Proisy, X. Descombes, G. le Maire, Y. Nouvellon, J. L. Stape, G. Viennois, J. Zerubia, P. Couteron, "Mapping local density of young Eucalyptus plantations by individual tree detection in high spatial resolution satellite images,"Forest. Ecol. Manag., v. 301, pp. 129-141, Aug., 2013.

[29] C. Wittmann, H. Pfanz, "The optical, absorptive and chlorophyll fluorescence properties of young stems of five woody species," Environ. Exp. Bot., v. 121, pp. 83-93, Jan., 2016.

[30] A. Girma, A. K. Skidmore, C. A. J. M. De Bie, F. Bongers, M. Schlerf, "Photosynthetic bark: use of chlorophyll absorption continuum index to estimate Boswellia papyrifera bark chlorophyll content," Int. J. Appl. Earth Observ. Geo, v. 23, pp. 71-80, Aug., 2013.

[31] G. P. Asner, C. A. Wessman, D. S. Schimel, S. Archer, "Variability in leaf and litter optical properties: implications for BRDF model inversions using AVHRR, MODIS, and MISR," Remote Sens. Environ., v.63, no. 3, pp. 243-257, Mar., 1998.

[32] C. Stone, L. Chisholm, N. Coops, "Spectral reflectance characteristics of eucalypt foliage damaged by insects," Aust. J. Bot., v. 49, no. 6, pp. 687-698, 2001.

[33] R. Houborg, H. Soegaarda, E. Boegh, "Combining vegetation index and model inversion methods for the extraction of key vegetation biophysical parameters using Terra and Aqua MODIS reflectance data," Remote Sens. Environ., v. 106, no. 1, pp. 39-58, Jan., 2007.

[34] B. Pinty, J-L. Widlowski, M. Taberner, N. Gobron, M. M. Verstraete, M. Disney, F. Gascon, J-P. Gastellu-Etchegorry, L. Jiang, A. Kuusk, p. Lewis, X. Li, W. Ni-Meister, T. Nilson, P. North, W. Qin, L. Su, S. Tang, $R$. Thompson, W. Verhoef, H. Wang, J. Wang, G. Yan, H. Zang, "RAdiation transfer Model Intercomparison (RAMI) exercise: results from the second phase," J. Geophys. Res., v. 109, no. D6, pp. 1-19, Mar., 2004.

[35] J-L. Widlowski, C. Mio, M. Disney, J. Adams, I. Andredakis, C. Atzberger, J. Brennan, L. Busetto, M. Chelle, G. Ceccherini, R. Colombo, J-F. Côté, A. Eenmäe, R. Essery, J-P. Gastellu-Etchegorry, N. Gobron, E. Grau, V. Haverd, L. Homolová, H. Huang, L. Hunt, H. Kobayashi, B. Koetz, A. Kuusk, J. Kuusk, M. Lang, P. E. Lewis, J. L. Lovell, Z. Malenovský, M. Meroni, F. Morsdorf, M. Mõttus, W. NiMeisterz, B. Pinty, M. Rautiainen, M. Schlerf, B. Somers, J. Stuckens, M. M. Verstraeteae, W. Yang, F. Zhao, T. Zenone, "The fourth phase of the radiative transfer model intercomparison (RAMI) exercise: actual canopy scenarios and conformity testing,"Remote Sens. Environ., v. 169, pp. 418-437, Nov., 2015.

[36] H. Shi, Z. Xiao, S. Liang, X. Zhang, "Consistent estimation of multiple parameters from MODIS top ofatmosphere reflectance data using a coupled soil-canopy-atmosphereradiative transfer model," Remote Sens. Environ., v. 184, pp. 40-57, Oct., 2016.

[37] Y. Xiao, W. Zhao, D. Zhou, H. Gong, "Sensitivity analysis of vegetation reflectance to biochemical and biophysical variables at leaf,canopy, and regional scales," IEEE Trans. Geosci. Remote Sens., v. 52, no. 7, pp. 4014-4024, July, 2014

[38] G. le Maire, C. François, K. Soudani, D. Berveiller, J-Y. Pontailler, N. Bréda, H. Genet, H. Davi, E. Dufrêne, "Calibration and validation of hyperspectral indices for the estimation of biochemical and biophysical parameters of broadleaves forest canopies," Remote Sens. Environ., v. 112, no. 10 , pp. 3846-3864, Oct., 2008. 
[39] M. Rautiainen, P. Stenberg, T. Nilson, A. Kuusk, "The effect of crown shape on the reflectance of coniferous stands," Remote Sens. Environ., v. 89, no. 1, pp. 41-52, Jan., 2004.

\section{FIGURES}

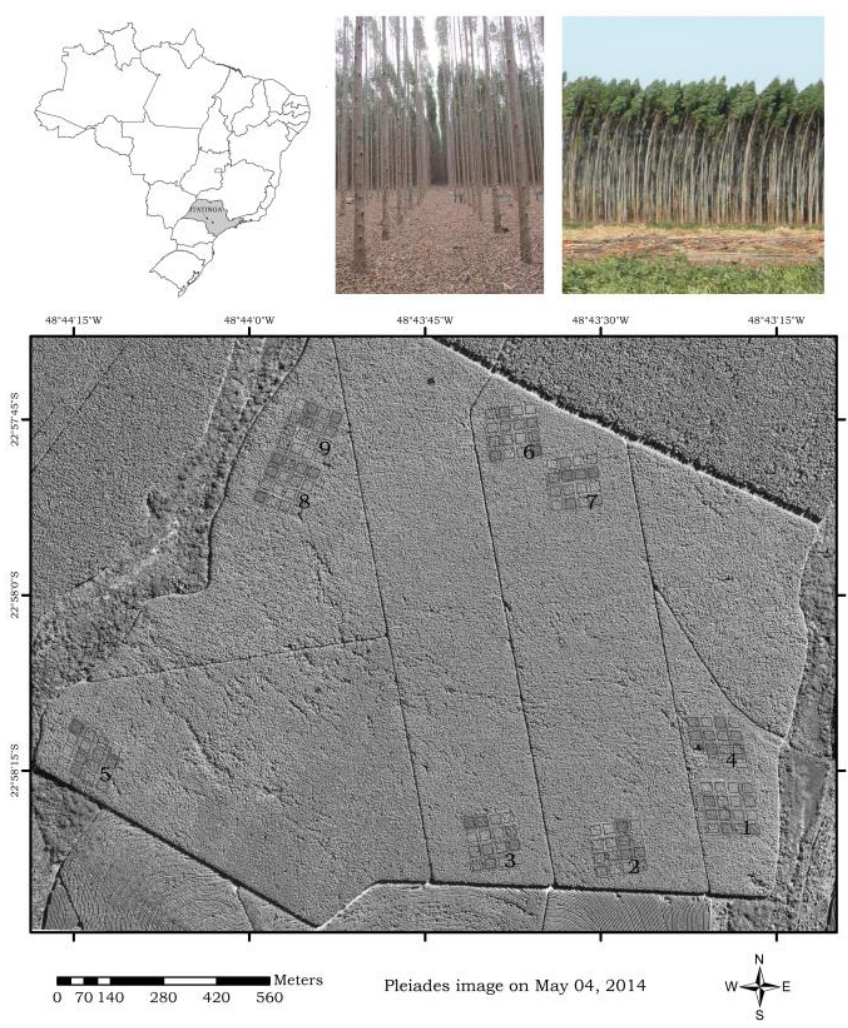

Fig.1. Location of the study site. Grey rectangles are the location of the genotype plots inside each block (with the block number). For each block, there are 16 plots (one plot per genotype) each including 12 rows of 16 trees, planted at a spacing of $2 \mathrm{~m}$ within rows and $3 \mathrm{~m}$ between rows. The picture is representative of eucalypts plantations on the trial experiment.
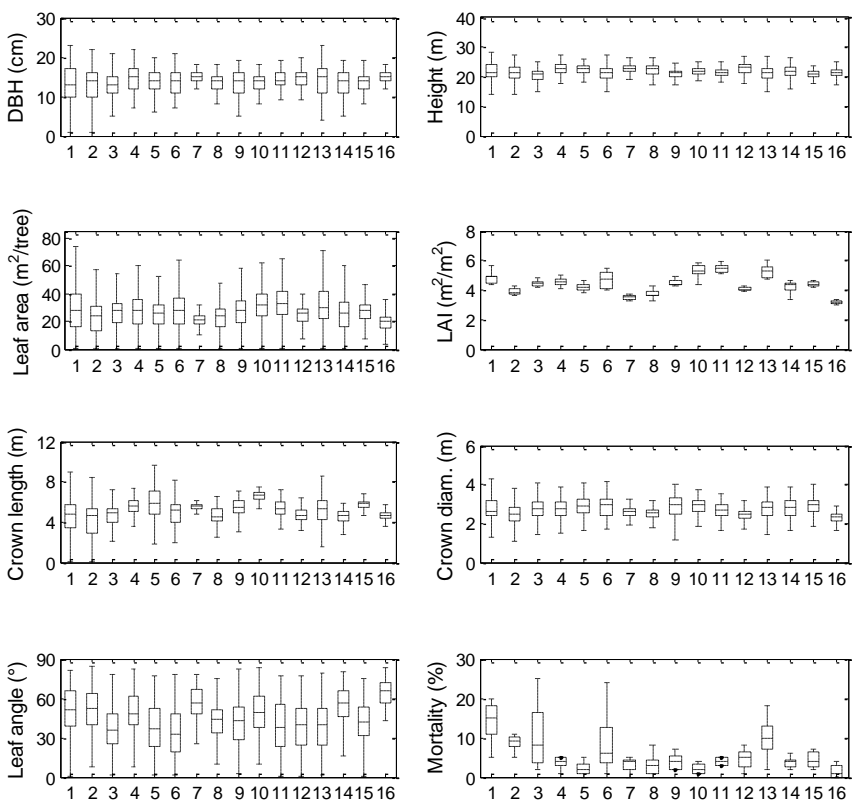
Genotypes
Fig. 2. Main stand structural characteristics (diameter at breast height - DBH, tree height, tree leaf area, leaf area index - LAI, crown length, crown diameter, leaf inclination angle and mortality) of the 16 genotypes on May, 2014. Mortality represents the percent of dead trees in each block per genotype. Lines inside boxes are the median values, inferior and superior boxes limits are the first and third quartiles, respectively; and error bars outside boxes extend from minimum and maximum values within 3 standard deviations. Variability considered here is the tree-scale variability considering all blocks. Mortality and LAI variability is inter-block variability.
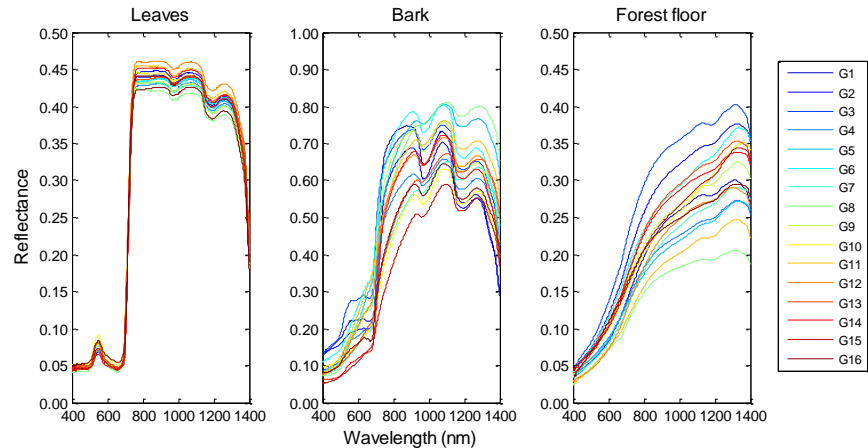

Fig. 3. Leaves, bark and forest floor optical properties (reflectance) for the 16 genotypes (labeled as G1 to G16) of the study area. The leaves reflectance was the adaxial reflectance of expanded mature leaves from the middle crown layer.
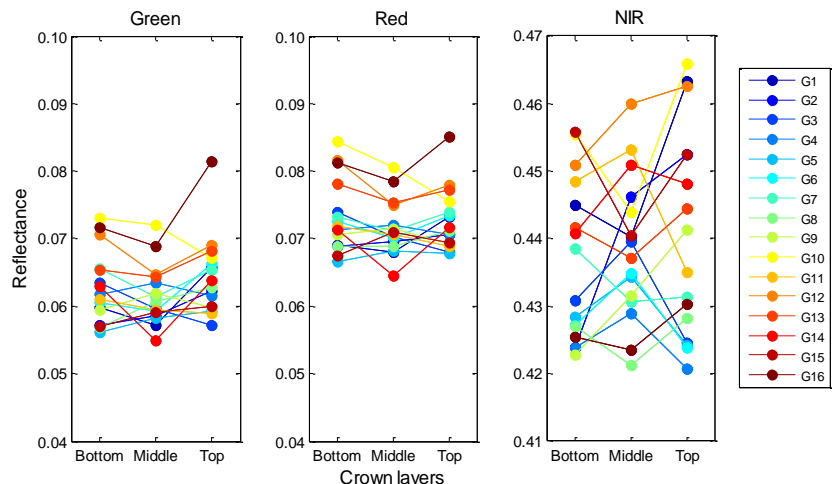

Fig. 4. Leaves reflectance in the green, red and near infrared regions at bottom, middle and top crown layer for the 16 genotypes (labeled as G1 to G16).

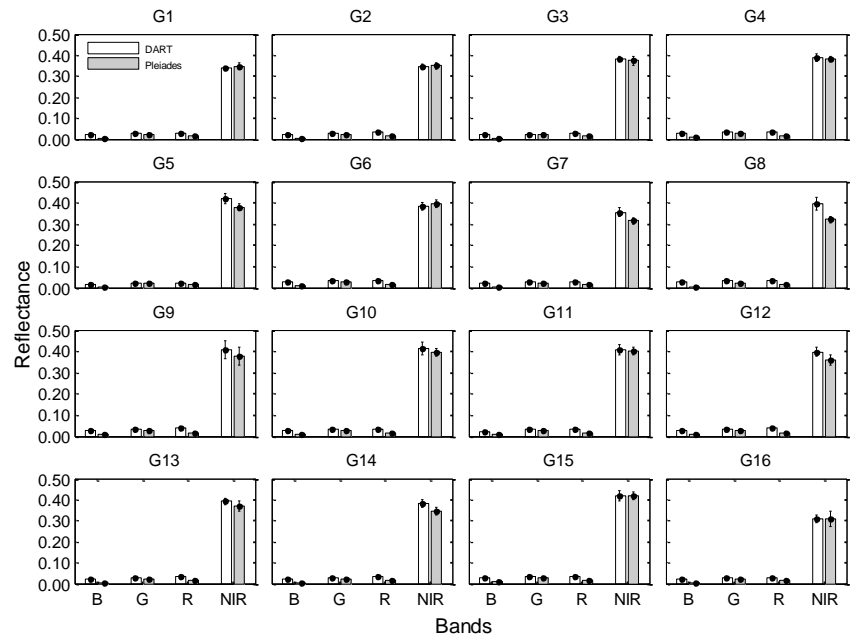

Fig. 5. DART (light gray) and Pleiades (dark gray) mean top of canopy (TOC) reflectance of four bands ( $\mathrm{B}=$ blue, $\mathrm{G}=$ green, $\mathrm{R}=\mathrm{red}, \mathrm{NIR}=$ near infrared) for each genotype averaged for all blocks and subplots. Lines in each bar represent the standard deviation for blocks. 


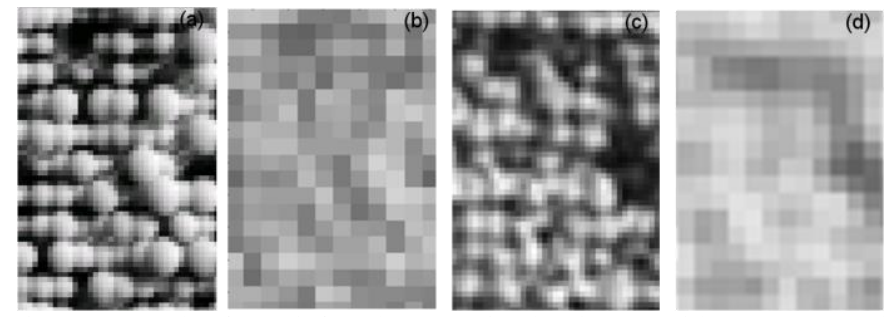

Fig. 6. Example of near infrared DART simulated scene with $0.50 \mathrm{~m}$ (a) and $2 \mathrm{~m}$ (b) of spatial resolution, panchromatic Pleiades image(c) with $0.50 \mathrm{~m}$ and near infrared Pleiades image with $2 \mathrm{~m}$ of spatial resolution for the genotype 14 in the block 4 .
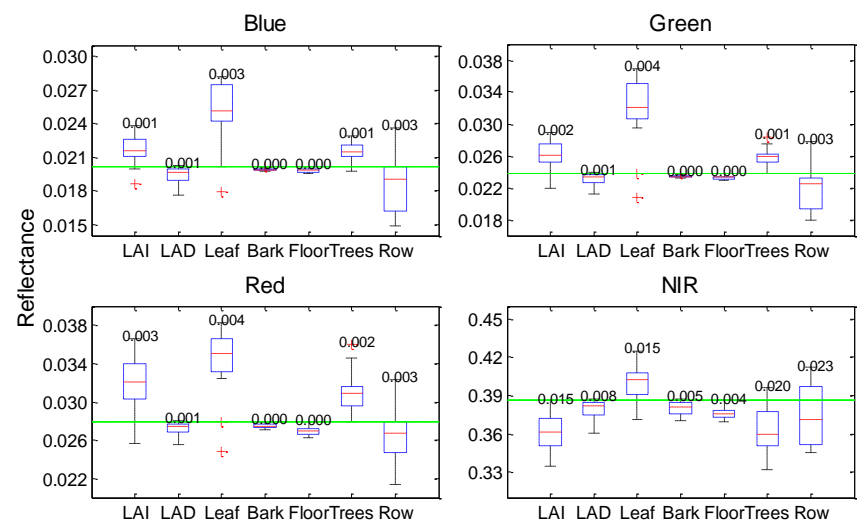

Parameters

Fig. 7. Sensitivity analysis of the reflectance in blue, green, red and near infrared bands relative to stand parameters (respectively, LAI, LAD, leaf, bark and forest floor reflectance, trees dimensions and row azimuth). Boxplot definition is given in Fig. 2. Dashed green line represents the TOC reflectance of the genotype 3 (reference). Numbers above each boxplot are the standard deviation. Red crosses are the outliers values. 